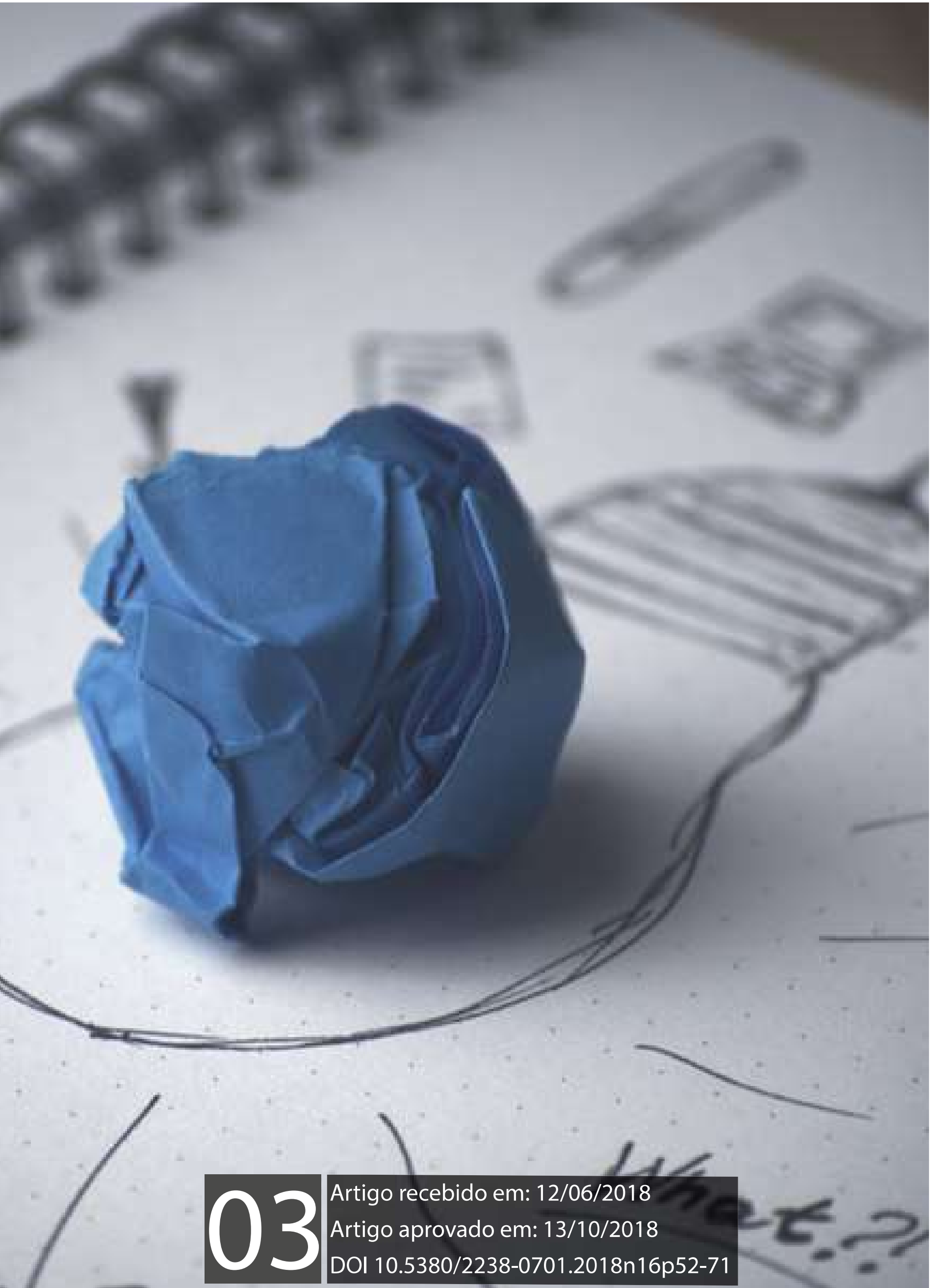


práticas institucionalizadas; campo da publicidade; modelo de negócios; tensionamentos e rupturas. 


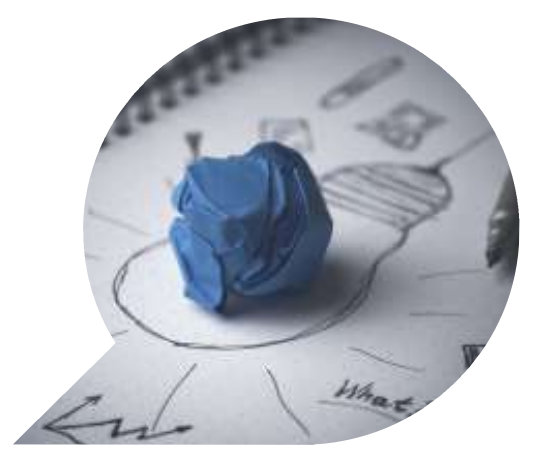

\section{Identificando práticas institucionalizadas na fala dos profissionais de agências de propaganda ${ }^{1}$}

\section{LUCAS SCHUCH ${ }^{2}$}

JULIANA PETERMANN ${ }^{3}$

Resumo: Neste artigo organizamos os primeiros movimentos de aproximação em relação ao nosso objeto de pesquisa. Para isso, definimos como objetivo central analisar aspectos do mercado publicitário, a partir do conceito de campo (Bourdieu, 1989), contrapondo práticas institucionalizadas (Berger e Luckmann, 1985) a movimentos de revisão ou de manutenção frente a tais práticas. Partimos da análise do podcast Código Aberto, procurando identificar na fala de profissionais que atuam em agências de propaganda, aspectos que revelem tensionamentos contemporâneos do campo da publicidade. ${ }^{4}$

1 Trabalho originalmente apresentado no VIII Pró-Pesq PP - Encontro de Pesquisadores em Publicidade e Propaganda. De 24 a 26/05/2017. CAC/UFPE.

2 Mestrando no programa de Pós Graduação em Comunicação da Universidade Federal de Santa Maria. Pesquisador

do grupo Nós Pesquisa Criativa. E-mail: schuch.lucas@gmail.com

3 Professora no Programa de Pós-graduação em Comunicação e no Departamento de Ciências da Comunicação da Universidade Federal de Santa Maria. Doutora em Ciências da Comunicação pela Universidade do Vale do Rio dos Sinos. Coordenadora do grupo Nós Pesquisa Criativa E-mail: petermann@ufsm.br

40 presente trabalho foi realizado com apoio da Coordenação de Aperfeiçoamento de Pessoal de Nível Superior - Brasil (CAPES) - Código de Financiamento 001 
Resumen: En este artículo organizamos los primeros movimientos de aproximación en relación a nuestro objeto de investigación. Para ello, definimos como objetivo central analizar aspectos del mercado publicitario, a partir del concepto de campo (Bourdieu, 1989), contraponiendo prácticas institucionalizadas (Berger y Luckmann, 1985) a movimientos de revisión o de mantenimiento frente a tales prácticas. Partimos del análisis del podcast Código Aberto, buscando identificar, en el habla de profesionales que actúan en agencias de propaganda, aspectos que revelan tensos contemporáneos del campo de la publicidad.

Abstract: In this article we will organize the first approximation movements in relation to our research object. For this, we define as central objective to analyze aspects of the advertising market, starting from the field settings (Bourdieu, 1989), opposing institutionalized practices (Berger and Luckmann, 1985) to revision or maintenance movements against such practices. We start from the analysis of the Código Aberto podcast trying to identify, in the speech of professionals working in advertising agencies, aspects that reveal contemporary tensions in the field of advertising.

Palavras-Chave: práticas institucionalizadas; campo da publicidade; modelo de negócios; tensionamentos e rupturas. 


\section{Introdução}

Este texto trata do primeiro movimento de exploração e de construção do objeto de pesquisa proposto pelo pesquisador como projeto de pesquisa de mestrado. Partimos do interesse de analisar a publicidade como um campo, constituído por práticas institucionalizadas, por tensionamentos constantes e por crescentes movimentos de ruptura. Procuramos identificar as transformações que estão ocorrendo no dia a dia de uma agência que dizem respeito, por exemplo, aos questionamentos sobre o modelo de negócios e as alterações de processos nessas empresas.

Para dar início a estes questionamentos e fazer um primeiro sobrevôo sobre nosso objeto de pesquisa, este artigo se propõe a responder a seguinte questão: observando pelo viés da prática publicitária, quais são os movimentos de revisão e/ou de manutenção de determinadas práticas institucionalizadas que podemos observar na fala dos profissionais entrevistados no podcast Código Aberto?

Para tal, analisaremos a fala de dois profissionais atuantes no mercado da propaganda, em entrevistas ao podcast Código Aberto, procurando indícios de práticas institucionalizadas, que aqui trataremos, por hora, como «mecanismos de manutenção». Por outro lado, buscaremos também por manifestações que revelem a intenção de romper com tais práticas, promovendo, assim, possíveis modificações. Tais intenções serão tratadas aqui como "mecanismos de revisão".

Os mecanismos de manutenção que observamos no discurso dos publicitários entrevistados, serão analisados a partir do conceito de institucionalização proposto por Berger e Luckmann (1985). Isso porque, a partir de nossa pesquisa de mestrado, percebemos o contexto atual do campo da propaganda marcado por tensionamentos que conduziriam a mudanças estruturais nos modelos de negócios tradicionais.

No entanto, percebemos também que, no contexto das agências, existe certo conformismo com as velhas práticas de se fazer propaganda. Assim, as práticas institucionalizadas, que podem ser definidas como ações repetidas diversas vezes ${ }^{1}$, acabam se tornando mecanismos de manutenção por representarem esquemas de conformismo. Explicamos: percebemos apego a tais práticas à medida que elas se tornam hábitos.

No âmbito da análise que estamos propondo aqui destacamos: trata-se apenas de um movimento inicial e exploratório da pesquisa, de aproxi-

1 Ver Berger e Luckmann, 1985, p. 77 
mação com nosso objeto de estudo. Assim, quando analisamos a fala dos profissionais entrevistados no Podcast Código Aberto temos ciência de que estamos diante de um recorte e que seria necessário, por exemplo, uma entrevista em profundidade com estes profissionais como forma de complementação e de verificação daquilo que identificamos em nossa análise. No entanto, por ser este um movimento inicial da pesquisa, extrapolaria nossos objetivos com o artigo. Mesmo assim, sempre que sentirmos necessidade, relativizaremos estes apontamentos, pois as falas aqui apresentadas podem não expressar o contexto e pensamento total dos entrevistados citados.

Neste momento se faz necessária rápida alusão ao conceito de campo proposto por Pierre Bourdieu, para que possamos organizar a definição daquilo que estamos tratando como mecanismos de manutenção e mecanismos de revisão do campo (do qual fazem parte as agências de propaganda e mais um conjunto de instituições como os eventos, os cursos de graduação, os sindicatos e as organizações de profissionais, veículos de comunicação, os consumidores,...).

Para Bourdieu um campo social é um espaço no qual se travam disputas simbólicas de poder entre atores dominantes e dominados. Petermann, ao discutir a noção de campo de Bourdieu, afirma que esta "permite a elaboração de leis gerais, que determinam sobre as disputas que acontecem no interior de diferentes campos e destes com os demais que o cercam" (PETERMANN, 2011, p.84).

Ainda para Petermann, o conceito de campo, proposto por Bourdieu, "permite o entendimento da construção de sistemas de percepções, que não tem aparentemente uma lógica, pois são fruto de um complexo sistema que pré-determina modos de fazer". É por aí que observaremos estes modos de fazer, explicitados na fala dos profissionais de agência, no podcast Código Aberto.

O conceito de campo de Bourdieu traz, consequentemente, outros apontamentos importantes como sua definição de campo de forças, como um "conjunto de relações de forças objetivas impostas a todos os que entrem nesse campo e irredutíveis às intenções dos agentes individuais ou mesmo às interações diretas entre os agentes" (BOURDIEU, 1985, p.134), ou seja, são forças do próprio campo que independem às intenções individuais dos agentes, no nosso caso, os próprios publicitários. Assim, neste artigo estamos nos referindo a uma parte do campo publicitário, ou, alguns agentes. Mais especificamente às agências de propaganda e modelos de negócio tradicionais, sabendo que também compõem o campo tantas outras instituições como as que já citamos. 


\section{Práticas Institucionalizadas}

Logo no início da exposição sobre o conceito de institucionalização, Berger e Luckmann nos dão um indício do quão presente essas práticas estão nas nossas vidas: "Toda atividade humana está sujeita ao hábito. Qualquer ação frequentemente repetida torna-se moldada em um padrão" (BERGER e LUCKMANN, 1985, p. 77). Sendo assim, além de estar intrínseco ao comportamento humano é importante que não vejamos os hábitos por um viés pejorativo, pois como colocam os autores, atuam como práticas que libertam o indivíduo e lhes fornecem ganho de tempo e de energia.

Ainda neste sentido, os autores nos trazem um olhar importante sobre estas práticas quando afirmam que "o fundamento da atividade tornada habitual abre o primeiro plano para a deliberação e a inovação", ou seja, as práticas tornadas habituais também contribuem para pensamentos inovadores. Pensamentos estes que são imprescindíveis em uma agência.

Os motivos que nos levam a questionar tais movimentos, partem da prática diária e da execução de tarefas rotineiras em uma agência de propaganda, no predomínio deste tipo de comportamento que visa a economia de esforços, e também no que diz respeito a tomadas de decisão que impactam mais diretamente no futuro do fazer publicitário, como, por exemplo, decisões sobre processos, departamentos em agências, remuneração, modelo de negócio, etc.

Para os autores "[o hábito oferece] um fundamento estável no qual a atividade humana pode prosseguir com o mínimo de tomada de decisões durante a maior parte do tempo, libertando energia para decisões que podem ser necessárias em certas ocasiões" (BERGER E LUCKMANN, 1985, p. 78). A nós parece que o problema se inicia na opção dos agentes do campo (publicitários) em definir qual situação/decisão necessita de mais ou menos energia, e as que devem ser tomadas, seguindo determinado status quo.

São estas práticas institucionalizadas então, que iremos entender como "mecanismos de manutenção" por parte dos agentes deste campo. Não é possível pensar em uma instituição, que não seja regida por práticas institucionalizadas e sujeitas à mecanismos de controle social, ou de manutenção destas, pois "o controle social primário é dado pela existência de uma instituição enquanto tal. Dizer que um segmento da atividade humana foi institucionalizado já é dizer que este segmento da atividade humana foi submetido ao controle social (BERGER e LUCKMANN, 1985, p. 80).

$\mathrm{E}$ é a partir daqui que nos propomos a pensar também o momento em 
que estes mecanismos que mantêm e sustentam as práticas são colocados em xeque, a partir do que estamos chamando de "mecanismos de revisão". Neste sentido, Berger e Luckmann (1985, p.80) nos apontam que "novos mecanismos de controle só são exigidos se os processos de institucionalização não forem completamente bem sucedidos" .

O que percebemos também neste momento de estado da arte é que a decisão hegemônica do campo ainda é de aplicar a lógica do menor esforço, conservando as coisas como estão, justamente no que diz respeito às questões que nos parecem muito relevantes à prática publicitária. Para exemplificar essa situação citamos as sessões de Design Thinking propostas pela Fenapro ${ }^{2}$ em 2015 que reuniu 160 diretores e donos de agência do país inteiro, a partir de problemas conhecidos do campo, para encontrar uma saída para "a baixa percepção de valor dos 'produtos' mais preciosos da agência” (FENAPRO, 2015).

A saída encontrada por esta instituição e pelos participantes foi elaborar um manifesto e propor uma nova nomenclatura para os mesmos serviços prestados pelas agências. Percebemos aí uma tentativa de manutenção de práticas tradicionais, colocadas sob o jugo de uma nova nomenclatura, como uma tentativa de camuflar o problema que estavam se propondo a resolver. Este por si só, poderia ser entendido como um mecanismo de manutenção: na tentativa de apresentar-se reformulada, a velha propaganda apenas trocaria de nome, sem provocar alterações estruturais em suas práticas.

No entanto, ao longo de nossa pesquisa, por meio de análise documental de mídia especializada (até o presente momento estamos constituindo um banco de dados com reportagens, entrevistas e notícias de veículos como Meio e Mensagem, Projeto Draft e B9 e tantos outros), percebemos que existe certa movimentação de determinados agentes deste mesmo campo, que estão dispostos a promover transformações neste cenário, procurando revisar paradigmas do mercado publicitário. Por exemplo, identificamos que hoje o modelo de remuneração das agências está sendo revisto por novos modelos de negócio ${ }^{3}$; a estrutura piramidal das agências - na qual poucos lucram muito sobre o trabalhos de muitos outros; os padrões discursivos diluíram-se - tanto em termos de forma, quanto de conteúdo; os consumidores vêm assumindo papéis importantes de vigilância e de rei-

2 Disponível em <http://www.sinaprosc.com.br/fmanager/sinapro2017/pesquisas/arquivo1_1. pdf $>$ Acesso em 09 de outubro de 2018.

3 Disponível em <https://projetodraft.com/que-tal-uma-agencia-de-publicidade-sem-sede-sem-chefe-e-com-remuneracao-aberta-e-o-que-a-hu mans-propoe/> Acesso em: 30 de setembro de 2018. 
vindicações sobre os conteúdos publicitários ${ }^{4}$; os fatores tecnológicos modificam drasticamente todas as esferas da da propaganda; a estrutura tradicional dos departamentos está sendo questionada em função das próprias reformulações do campo ${ }^{5}$; os estudantes recém saídos da academia não dispostos a trabalhar em ambientes como as agências ${ }^{6}$, entre muitos outros.

Todos esses tensionamentos que citamos já apareceram no decorrer de nossa pesquisa como problematizações latentes ao campo publicitário neste momento de transformação. No entanto, apesar de tantos pontos que parecem exigir reformulações e rompimentos, parte considerável do mercado permanece inerte, optando por conservar os modelos e práticas da propaganda que derivam dos anos 80 ou encontrando dificuldades para promover rupturas.

Inquieta-nos como (e se) estes tensionamentos podem deslocar efetivamente o modelo de negócios de uma agência de propaganda, visto que são exigências tanto de agentes internos, quanto externos: tais reformulações podem ser propostas, por exemplo, pelos clientes da agência ou pela própria sociedade ${ }^{79}$, como vimos nos exemplos que trouxemos.

\section{Podcast Código Aberto}

O objeto que iremos analisar chama-se Código Aberto, um podcast idealizado pelos fundadores do site de notícias B9 (www.b9.com.br), muito conhecido no meio publicitário por suas contribuições sobre criatividade, inovação e entretenimento.

Nas palavras dos idealizadores, os episódios deste podcast tratam-se de: "Conversas francas com os profissionais mais influentes do mercado, suas grandes ideias e o que pensam sobre o futuro da mídia, da tecnologia e da comunicação" ${ }^{\prime 10}$. Em cada episódio, os entrevistadores encontram um profissional do mercado, transitando entre presidentes e sócios de grandes

\footnotetext{
4 Disponível em <http://www.meioemensagem.com.br/home/marketing/2017/05/23/o-poder-das-marcas-sobre-os-consumidores-chegou-ao-fi m.html> Acesso em: 30 de setembro de 2018. 5 Disponível em <http://sxsw.meioemensagem.com.br/cobertura2017/2017/03/17/nao-podemos-mais-ser-apenas-agencias-de-publicidade/> Acesso em: 30 de setembro de 2018.

6 Disponível em <https://www.b9.com.br/68633/em-qual-empresa-voce-deseja-trabalhar-2016/>. Acesso em: 30 de setembro de 2018.

7 Em 2017, Wottrich apresenta a tese intitulada "Não podemos deixar passar: práticas de contestação da publicidade no início do século XXI". Nela a autora define o que seriam as práticas de contestação: um movimento que tem origem na esfera da recepção e que questiona a representação das mulheres na publicidade. As práticas de contestação representam um grande tensionamento no campo que conduzem a revisão tanto de discursos quanto de práticas.

8 Descrição do podcast disponível em http://www.b9.com.br/podcasts/codigoaberto/
} 
agências do país, até profissionais de marketing atuantes em empresas multinacionais, e suas opiniões sobre o futuro da comunicação em geral.

Para cumprir o objetivo deste artigo selecionamos dois episódios. $\mathrm{O}$ primeiro, com o publicitário Rodolfo Medina ${ }^{9}$. Rodolfo é presidente da agência ArtPlan, localizada em Brasília, e que atende atualmente contas como Rock In Rio, Coca-Cola Brasil e Amanco. Gravado no dia 27 de setembro de 2016.

O segundo episódio escolhido é o de número cinco, gravado no dia 5 de junho de 2016, com o então Vice-Presidente de Planejamento e sócio da agência LDC (antiga Loducca), e atual sócio proprietário da consultoria Ada Strategy, Ken Fujioka ${ }^{10}$.

Optamos por esta amostra e seleção destes episódios em específico, pois dentre os disponíveis deste podcast até então, eram os profissionais que já haviam passado por um maior número de agências e empresas de comunicação, e além disso, estavam hierarquicamente nos maiores cargos em suas corporações, e, portanto, possuíam a maior experiência sobre os modelos de produção de mensagens publicitárias.

É neste cenário que nos inserimos: tentando encontrar na fala destes dois profissionais vestígios de tensionamentos (de manutenção e revisão) do fazer publicitário. Dizemos vestígios, pois, analiticamente apenas poderemos fazer afirmações a partir da fala destes profissionais, e, portanto, não podemos afirmar que este é o pensamento total destes profissionais a respeito do que for trazido aqui.

\section{Mecanismos de revisão e Mecanismos de manutenção}

Neste tópico, indicaremos, a partir da análise do Podcast, aqueles que nos parecem mais como mecanismos de revisão ou mecanismos de manutenção de práticas institucionalizadas. Sendo que os mecanismos de revisão podem ser entendidos como ações que venham a desestabilizar as práticas institucionalizadas, e que inevitavelmente conduzem os profissionais e o campo do fazer publicitário a reestruturações, visando o acompanhamento destas mudanças. Ações estas que podem vir do próprio campo, ou ainda de outros, como do setor econômico quando nos referimos a movimentos mercadológicos do país, ou da sociedade como um todo. Isso acontece

9 Episódio disponível em: http://www.b9.com.br/67285/podcasts/codigoaberto/codigo-aberto-rodolfo-medina-presidente-artplan/

10 Episódio disponível em: http://www.b9.com.br/65772/podcasts/codigoaberto/codigo-aberto-ken-fujioka-socio-e-vp-de-planejamento-ldc/ 
quando, por exemplo, percebemos discussões importantes como as relacionadas às questões de gênero no setor criativo ou sobre casos de racismo no mercado de trabalho publicitário ${ }^{1113}$ passam a permear o campo, provocando deslocamentos e rupturas no modelo hegemônico da propaganda. Já os mecanismos de manutenção são aqueles que visam conservar as práticas tal como estão, garantindo também a manutenção dos papéis institucionais e dos limites do campo.

Encontramos um primeiro mecanismo de revisão, que consideramos como externo ao campo, na fala do sócio diretor da LDC, Ken Fujioka. Quando questionado sobre o que seria melhor para uma marca em termos de posicionamento (ou um posicionamento construído por anos ou uma mudança no posicionamento a cada troca de agência, para que a área de planejamento dessa agência mostre o seu trabalho) ele pontua uma questão interessante e que vem a tensionar o esquema de agências tal como o conhecemos hoje. Com a dinâmica do mercado de clientes rotacionando-se muito rápido, a duração de um profissional de marketing em uma empresa é de cerca de 2 anos, e isso faz com que a agência

seja o agente que tem que fazer handover [prática conhecida como a passagem de mercado entre profissionais, clientes e agências], então entra um novo executivo e a agência faz essa integração do cliente, porque a agência está há mais tempo do que as pessoas da equipe do marketing lidando com a própria marca (FUJIOKA, Ken. São Paulo, Podcast Código Aberto, 30 jun.2016).

Sendo assim, conseguimos identificar uma movimentação por parte da agência em acompanhar também os movimentos de mercado, inclusive assumindo uma importante função de mediação entre a marca e seu público interno. Como também fica claro quando perguntado sobre a utilidade do profissional de planejamento em outras áreas que não uma agência, Fujioka afirma que as habilidades que ele tem vão ser úteis em diversas áreas. E traçando um paralelo com a área de redação ele afirma que: "Se um cara só sabe criar títulos, ele dificilmente vai ser útil em outro lugar. Talvez ele não seja útil nem mesmo em uma agência daqui pra frente" (FUJIOKA, Ken. São Paulo, Podcast Código Aberto, 30 jun.2016.).

Com esses apontamentos percebemos indícios de uma redefinição tanto das funções das agências, quanto das atuações dos próprios profissionais

11 Disponível em <http://www.meioemensagem.com.br/home/comunicacao/2017/08/21/debate-etnico-racial-chega-atrasado-as-agencias.html> Acesso em 30 de setembro de 2018. 
da propaganda, pois parece-nos que em todos os departamentos de uma agência estão sendo exigidos conhecimentos e habilidades novas, ou, alargamentos e convergências de determinadas áreas. Até então conhecimentos mais específicos e estanques pareciam ser suficientes. Este fator torna clara a alteração crescente das habilidades requeridas dos profissionais de uma agência. Poderíamos pontuar aspectos de possíveis deslocamentos nos contornos do habitus publicitário.

No entanto, em relação ao mesmo ponto, que demarca possíveis deslocamentos nos contornos do habitus, este entrevistado apresenta outro aspecto de manutenção: isso acontece quando ele questiona sobre a diferença entre um profissional de planejamento e um estrategista. Fujioka, aponta que as habilidades exigidas são parecidas, porém:

existe uma coluna vertebral, vamos dizer assim, do estrategista. Tanto que, no Grupo de Planejamento, que também eu estou presidindo no momento, a gente tem um curso de formação de planejadores, que ignora se o cara está em agência digital offline, ou dita online ou coisa do gênero. Ou de performance. É planejamento e pronto. É uma formação do planner, ele tem que estar preparado para trabalhar com estratégia. (FUJIOKA, Ken. São Paulo, Podcast Código Aberto, 30 jun.2016.)

Neste trecho, poderíamos identificar que uma prática nova provenientes de modelos e estruturas pouco convencionais de agências, sejam elas digitais, de performance e outras, acaba sendo pormenorizada em detrimento de uma prática mais enraizada. Visa a formação de um profissional de planejamento mais generalista, pouca adequada às especificidades dos modelos mais contemporâneos. Neste caso, poderíamos entender como um mecanismo de manutenção do campo porque estamos acompanhando, inclusive pela fala anterior do próprio entrevistado, movimentos de alteração no habitus ${ }^{12}$ (Bourdieu, 1989) do profissional de planejamento, que nesta proposição parece pouco considerado. Assim, pelos apontamentos de revisão e de manutenção identificados sobre o habitus do profissional de planejamento, a partir das falas destes entrevistados, e considerando o contexto atual, podemos questionar: ser um estrategista ou um planner hoje consiste na mesma atuação que a de alguns anos atrás?

Sobre estas mudanças no habitus do planejamento, o entrevistador

12 Conceito de Bourdieu (1989) conforme Petermann (2012): O conceito de habitus diz respeito àquilo que os homens fazem e como o fazem. Bourdieu fala de certa homogeneidade que rege as práticas e que se apresenta em constante processo de atualização: ao mesmo tempo em que se define como uma incorporação histórica e também reorganizada do cotidiano. 
questiona Ken, sobre o fato que o departamento de planejamento em agências começou como uma área de pesquisa e que hoje isso é uma prática de institutos e os próprios clientes vem investindo mais nessa área. $O$ entrevistador questiona também sobre como manter a relevância de um profissional de planejamento. $O$ entrevistado responde algo essencial para entendermos estas mudanças não apenas como aspectos relativos aos profissionais, mas que diz respeito ao cenário de publicidade como um todo: "O planejamento tem que entender (...) que o mercado está sofrendo mudanças, e que ele vai ter que entregar algumas coisas que não necessariamente ele estava treinado para entregar antes" (FUJIOKA, Ken. São Paulo, Podcast Código Aberto, 30 jun. 2016). Nossas investigações futuras pretendem identificar quais são estas novas entregas, para podermos de fato apontá-las como um mecanismo de revisão, ou se estas já não são práticas do mercado apenas sob outra nomenclatura.

Ainda em relação às transformações no entorno do profissional do planejamento outro aspecto pode ser destacado: o entrevistador considera sobre um possível êxodo de profissionais do mercado publicitário para startups e empresas nas quais é possível exercitar a criatividade, antes característica exclusiva das agências de propaganda, e o questiona sobre como as agências podem recuperar esses profissionais. $O$ entrevistado afirma que não sabe se essa resposta existe, mas que ele acha que existe a "chance de pegar o cara quando ele ainda está no comecinho. Eu sempre tive a filosofia, no planejamento, de ter estagiário, porque são caras que estão saindo ou ainda estão na faculdade, então tem poucos vícios, poucas certezas sobre o mercado" (FUJIOKA, Ken. São Paulo, Podcast Código Aberto, 30 jun. 2016). Obviamente que a intenção na colocação do entrevistado é de formar o melhor profissional possível, segundo seus ensinamentos, porém, como afirmamos anteriormente, em nosso embasamento teórico, a sustentação de algumas práticas nem sempre se dá de maneira consciente e aqui podemos identificar um mecanismo de conservação das práticas institucionais, pela transmissão dos modos de fazer de um agente institucional para outro recém chegado. São resultantes naturais de conservação, de um modo específico de ver o mundo e de também de atuação em conformidade com o próprio campo e com o habitus, visando a manutenção de ambos. Trata-se de movimentos de legitimação de modos de fazer e de portar-se no campo, passando de uma geração de profissionais para a geração seguinte.

Daí o porquê de apontarmos esse comportamento como um mecanismo de manutenção do campo e das práticas, quase como uma maneira de defesa 
em relação ao êxodo das agências para empresas mais jovens no mercado e que também permitam o exercício de práticas criativas. Conforme afirmam Berger e Luckmann, esta atitude pode não ser conscientes, e a intenção do entrevistado pode ter sido treinar um novo profissional sem os vícios dos quais ele não compactua, porém, pode transferir os seus hábitos, com os quais outros profissionais não concordam por sua vez, e assim sucessivamente.

Quando se trata das questões efetivas da reformulação do modelo de negócio revelam-se mecanismos de manutenção naquilo que diz respeito especialmente à hierarquia do trabalho, embora os mecanismos de revisão sejam preponderantes em outros aspectos. Em determinado trecho da entrevista, o entrevistador elenca startups e empresas ditas criativas, que estão adotando um modelo horizontalizado, sem o predomínio de relações hierárquicas entre pessoas. Trazendo isso para o mercado da propaganda, Fujioka afirma que eles também estão buscando na LDC (então agência do entrevistado) um modelo mais horizontal, inclusive fisicamente, derrubando algumas barreiras entre os setores tradicionais da agência.

Além disso, Ken Fujioka comenta a mudança na organização das equipes e estruturação física que está sendo proposta na agência LDC, e que em muito corrobora o nosso pensamento de que mantemos práticas institucionalizadas há muito tempo no mercado publicitário e que revela sua disposição para a revisão de determinados modelos desgastados em publicidade:

Então, essa organização teve esse pensamento, porque não abandonar uma estrutura, que a gente já traz desde a década de 60 , quase que por inércia, durante 50 anos, alegando que 'sempre foi assim'. Vamos guinar para uma coisa que se aproxima mais daquilo que a gente considera o melhor dela. Pelo menos, em tese, faz com que eles [os profissionais] tenham essa integração no dia a dia, e não em momentos pontuais. (FUJIOKA, Ken. São Paulo, Podcast Código Aberto, 30 jun.2016).

Porém, alterações estruturais são complexas e isso fica pontuado na seguinte fala do entrevistado: "você ainda vai ter gente cujo papel é de coordenação, então você não elimina essa necessidade". Tal afirmação parece conotar a necessidade de conservação de um modus operandi: busca atualização em determinados níveis, porém conserva alguns esquemas de funcionamento em termos de posições de trabalho. Assim, embora haja disposição dos agentes institucionais para a revisão de determinadas práticas, a efetivação de transformações estruturais organizacionais é um pouco mais complexa.

Do ponto de vista dos mecanismos de revisão e de manutenção institu- 
cional, identificamos outro trecho que diz respeito aos festivais de criatividade, mais especificamente sobre o Festival de Cannes. Ken Fujioka afirma que não devemos ser ingênuos, e portanto precisamos entender o festival como um negócio. Entender o festival como um negócio pode representar um mecanismo de revisão das práticas, pois aplica sobre estes uma análise crítica. E do ponto de vista de negócio ele funciona bem, visto que nas palavras do entrevistado:

sendo um negócio, existe um regulamento, e vai se jogar conforme o regulamento. Você concorda com o regulamento? Eu não concordo com várias coisas do regulamento. Mas se ele é assim, enquanto não mudar, eu vou jogar segundo esse regulamento. (FUJIOKA, Ken. São Paulo, Podcast Código Aberto, 30 jun.2016).

No entanto, se o entrevistado pretende jogar o jogo conforme as regras, acaba configurando um movimento de manutenção institucional, por outro lado. Sendo assim, em relação aos festivais também identificamos uma perspectiva dupla: a intenção de revisão de determinados aspectos, a partir de uma perspectiva crítica do evento de premiação, porém ao final, certa adequação institucional. Interessante pensar este mecanismo duplo da perspectiva de economia de energia a partir de Berger e Luckmann (1985): altera-se a instituição em certa medida, porém conserva-se a sua estrutura, reservando economia para outros processos.

Agora analisando a fala do presidente da ArtPlan, Rodolfo Medina, quando questionado sobre os maiores desafios do campo comunicacional, especificamente o da publicidade, ele aponta que o mundo mais ágil como conhecemos hoje e todas as transformações que ocorrem diariamente não é original da geração a qual ele e outras vozes importantes do mercado pertencem. Ele afirma que

nós todos que estamos na liderança dessa conversa migramos pra esse mundo. A galera que está vindo a partir de agora, já nasceu num mundo diferente, e o modo de pensar é diferente. Então o que a gente tem que fazer é beber no conhecimento dessa galera nova. (MEDINA, Rodolfo. São Paulo, Podcast Código Aberto, 27 set.2016).

Entendemos este como sendo um dos principais tensionadores ao mercado de publicidade hoje: o fato de que o mercado será abastecido por profissionais que já não tem a mesma referência de agências de publicidade que seus antecessores tinham. Estamos acompanhando uma geração que 
já possui como modelos de negócio, outras possibilidades de trabalho e de saídas para a publicidade. Jovens que já possuem projeções a respeito do futuro do trabalho e do seu próprio futuro, especialmente na propaganda. Assim, assumir o potencial da juventude parece ser um importante movimento de revisão das práticas institucionais.

Por outro lado, no que diz respeito ao futuro das agências, especialmente em relação à remuneração, identificamos um movimento bastante tradicional de preservação: a necessidade de identificar responsáveis por problemas institucionais fora da própria instituição. Neste trecho, Rodolfo Medina analisa a má prática por parte dos clientes de remuneração incompatível com as agências: "o modelo passa por pagar as agências, para ela contratar profissionais. Então, é uma coisa tão engraçada que se discute remuneração de agência, e na outra ponta o cara tá injetando 100 milhões de verba" (MEDINA, Rodolfo. São Paulo, Podcast Código Aberto, 27 set. 2016). Entendemos esse movimento como um mecanismo de manutenção, pois nos parece que vem a transferir a responsabilidade sob o modelo que se apresenta, sem propor algum agente transformador, elencando razões alheias ao próprio negócio. Ainda nesse sentido Medina afirma que "o cliente precisa entender que precisa pagar direito pra ter os melhores profissionais envolvidos e ter uma entrega e um resultado melhor". Neste caso, uma prática de revisão institucional poderia propor a análise de aspectos deficitários das próprias práticas das agências de publicidade, pois o valor do profissional ou das suas práticas é uma resultante: algo que é conferido a ele por um reflexo de sua atuação como um todo, constituindo, assim, uma imagem positiva ou negativa.

Como, por exemplo, neste trecho, quando, a partir de uma reflexão e análise das próprias práticas, o presidente da ArtPlan propõe um movimento de revisão, afirmando que:

Lá na ArtPlan, nós precisávamos propor uma proposta de valor diferenciada quando chegamos no Rio de Janeiro, para nos diferenciarmos. Então a gente colocou pessoal qualificado de branding, de e-commerce etc. Isso não necessariamente a remuneração tradicional de agência paga. Isso é investimento. E isso tem dado muito resultado. (MEDINA, Rodolfo. São Paulo, Podcast Código Aberto, 27 set.2016.)

Ou seja, na tentativa de passar por cima de um mecanismo de resistência e uma prática já institucionalizada do mercado (remuneração incompatível das agências), propõe um movimento de qualificação profissional para agregar valor. 
Este tipo de análise, que parte de uma visão crítica de dentro da própria instituição acontece, por exemplo, neste trecho, quando Medina aponta importante tensionamento sobre as fusões de agências com grupos multinacionais. Em um mundo no qual a agência é muito demandada em relação a agilidade, qualquer processo de burocratização não favorece as mudanças. Assim, identificamos mecanismo de revisão nas seguintes palavras:

Quando você fala em um mundo que vai reinventar as formas de relacionamento entre cliente e agência. Um mundo que precisa trazer pra dentro da conversa do nosso negócio, outros agentes, que também contribuem com esse produto final. Quando você tem uma agência independente, com capacidade de investimento e reação mais rápida, você tem chance de ser líder de agilidade. (MEDINA, Rodolfo. São Paulo, Podcast Código Aberto, 27 set.2016).

Portanto, na fala de ambos entrevistados, o que parece ser preponderante são mecanismos duplos: que propõem aspectos de revisão por um lado e de manutenção por outro. Isso acontece também quando Medina é questionado sobre o modelo de concorrências ${ }^{13}$ entre agências: ele diz "Se você me perguntar eu prefiro ganhar conta sem concorrência, mas, faz parte. Tem que entrar em concorrência e a gente entra em concorrência, sim". Aqui essa simples concordância com essa imposição, pode ser entendida como um mecanismo de manutenção. Porém minutos depois, na mesma entrevista, ele propõe algumas sugestões de como modificar esse cenário, conservando a prática, porém tornando-a mais justa.

Aqui conseguimos identificar um ponto chave no que diz respeito às práticas institucionalizadas: questionar pequenos aspectos de uma prática, e propor pequenas mudanças, mantém a prática enraizada, sem provocar a ruptura necessária para que tal prática seja revista. A proposta parece ser de mudanças em alguns níveis, porém não estruturais.

Mais uma vez é importante termos em mente que estes mecanismos, que se constituem de movimentos de conservação ou de revisão, são relativos a movimentações, internas e externas ao mercado. E que quando propõem alterações institucionais estruturais possuem uma missão bastante complexa pela frente, por isso, os agentes circulam entre duas maneiras tão distintas de atuação, propondo revisões até certo limite.

Portanto, fica claro, em duas falas tão recentes de profissionais do mer-

13 Concorrências tratam-se de diversas agências concorrendo criativamente pelo direito de atender a conta de um único cliente. 
cado, que as agências ainda buscam uma melhor maneira de quebrar esses antigos mecanismos de manutenção de práticas institucionalizadas, que permeiam o campo por anos movidas por estes outros mecanismos de revisão que exigem uma atualização de todo o cenário que envolve uma agência de publicidade.

\section{Considerações Finais}

Acima de tudo, é preciso dizer uma última vez, que baseamos esta análise do ponto de vista de entrevistas de profissionais de propaganda à um veículo de comunicação. Dado os limites do nosso corpus fica evidente a necessidade de avançarmos nossa pesquisa com estes profissionais para podermos avaliar suas opiniões de maneira mais aprofundada. Contudo, a presente incursão teórica nos auxilia a, como pretendíamos, encontrar vestígios de mecanismos de manutenção e revisão das práticas, e portanto, como vestígios, precisarão ser melhor investigados no futuro para conclusões mais definitivas.

Partindo do conceito de campo proposto por Pierre Bourdieu, nos interessa pesquisar sobre o modelo atual de agências de propaganda e as transformações que observamos neste contexto. Iniciando de uma análise do conceito de práticas institucionalizadas, definimos o que seriam "mecanismos de manutenção" e também "mecanismos de revisão".

Se observarmos a data recente das entrevistas, também é possível identificar o quão latente é este assunto, evidenciando as possibilidades de estudos a serem feitos nesse sentido, respondendo positivamente a um dos objetivos deste artigo, de verificar a sustentação da pesquisa que está em curso.

É importante deixar mais uma vez registrado, que as atitudes apontadas como mecanismos de manutenção, e muito exploradas nas teorias de Berger e Luckmann como práticas institucionalizadas, não são tomadas com consciência por parte dos agentes do campo, no nosso caso os publicitários. Como dissemos, é nosso interesse com este artigo avaliar se estas tomadas de decisão que privilegiam a economia de esforços seriam maioria nesses espaços em detrimento de movimentos de revisão das práticas. Podemos perceber na fala destes profissionais que em certos momentos eles defendem a transformação e a mudança de velhos hábitos, e em outros momentos conservam tantos outros hábitos. Tal qual propunha Berger e Luckmann, dizendo que em alguns momentos romperemos com certos hábitos, em outros momentos não. 
Devido aos limites deste artigo, não era nossa intenção uma análise aprofundada, e sim identificar o espaço para o desenvolvimento de uma pesquisa neste sentido, o que se mostrou positivo. É possível perceber que o modelo de agências está em transformação que podem ser acionadas por questões internas, econômicas, ou outras variáveis externas.

Simplificando ao máximo o raciocínio, ao que parece, transformações nas práticas ocorrem quando a quantidade de mecanismos de revisão é superior à quantidade e a força dos mecanismos de manutenção do campo ao qual se analisa.

\section{Referências Bibliográficas}

BERGER, Peter L. E LUCKMANN, Thomas. A construção social da realidade. Tratado de Sociologia do Conhecimento. Petrópolis: Ed. Vozes, 1985.

BOURDIEU, Pierre. O Poder simbólico. Rio de Janeiro: Ed. Bertrand Brasil, 1989. FUJIOKA, Ken. São Paulo, Podcast Código Aberto, 30 jun.2016. Entrevista a Carlos Merigo.

MEDINA, Rodolfo. São Paulo, Podcast Código Aberto, 27 set.2016. Entrevista a Juliana Wallauer.

PETERMANN, Juliana. Do sobrevôo ao reconhecimento atento: a institucionalização da criação publicitária, pela perspectiva do Habitus e dos capitais social, cultural e econômico. São Leopoldo: UNISINOS, 2011, 408p. Tese. Unidade Acadêmica de Pesquisa e Pós-Graduação.

WOTTRICH, Laura. "Não podemos deixar passar: práticas de contestação da publicidade no início do século XXI. Tese (Doutorado em Comunicação e Informação), Programa de Pós-Graduação em Comunicação e Informação/UFRGS, Porto Alegre, 2017. 
AÇÃO MIDIÁTICA, n.16. Jul./Dez. 2018. Curitiba. PPGCOM-UFPR. ISSN 2238-0701

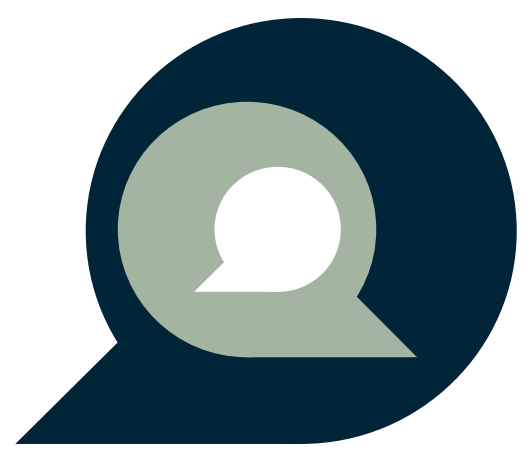

